\title{
Understanding the Success of Sharing Economy Startups: A Necessary Condition Analysis
}

\author{
Quang "Neo" Bui \\ Rochester Institute of Technology \\ qnbbbu@rit.edu
}

\author{
Son Ngoc Bui \\ Texas A\&M University-Commerce \\ Son.Bui@tamuc.edu
}

\begin{abstract}
Sharing economy businesses such as Uber and AirBnB have disrupted the traditional business models and drawn considerable attention from researchers. While many sharing economy startups are found, a majority of them go unnoticed and fail to reach a critical mass for survival. Prior studies have mostly focused on consumer engagement as success factors for sharing economy businesses. Yet, there is a scarcity of research on success factors at the entry level of sharing economy businesses, namely, the fundraising rounds. This study uses a Necessary Condition Analysis (NCA) on 99 sharing economy startups to explore how human capital, innovativeness, and entrepreneurial footprint impact their fundraising success. Our findings show a large necessary effect for human capital and entrepreneurial footprint, and a medium effect for innovativeness on fundraising success. Additionally, firms only need a range of $30 \%$ to $40 \%$ level of three factors to achieve at least $40 \%$ level of fundraising success.
\end{abstract}

\section{Introduction}

In recent years, the success of companies such as Uber and AirBnB has drawn considerable attention to the phenomenon of the sharing economy. This disruptive business model is broadly defined as "a socioeconomic system that allows peers to grant temporary access to their underutilized physical and human assets through online platforms" [1](p. 71). Unlike other types of startups, sharing economy allow individuals to engage in entrepreneurial activities (i.e., peer-to-peer transactions) without significant capital investment, using only existing and unused personal assets [2]. This unique aspect has attracted an army of "gig workers" to engage in the sharing economy; and it is estimated that between $20 \%$ to $30 \%$ of the working population in the US and Europe are active members of a sharing economy platform [3]. The frenetic excitement of the sharing economy has led to billions of investments in sharing economy startups, with prominent companies such as Uber and AirBnB receiving over $\$ 100$ billion despite consistent operating losses (https://news.crunchbase.com/news/inside-theuber-s-1-revenue-growth-and-losses/).

Against this backdrop, researchers have started to examine the antecedents and effects of sharing economy successes or failures $[4,5,1,6]$. Yet, prior studies have mostly focused on consumer engagement as a predictor for the success of sharing economy businesses [7]; but there is a real scarcity of research for success factors at the entry level for the sharing economy [1]. This research gap is critical, given a significant number of sharing economy businesses cease their operations within three years of operations [5], and the Covid-19 pandemic has overwhelmingly worsened the performance of sharing economy businesses [8].

In this study, we seek to address the research gap by exploring the success factors associated with the success of sharing economy startups. Our research question is what factors are necessary conditions for the success of sharing economy startups? Going beyond the traditional econometrics approach often used in entrepreneurial research, we employ a novel method called Necessary Condition Analysis (NCA) to understand (1) what factors are necessary (but not sufficient) conditions for the success of sharing economy startups and (2) the degree of constraint such factors have on a given success level. The analysis was conducted on a dataset of 99 sharing economy startups listed in the Crunchbase database, a leading platform for venture capital crowdsourcing.

Our study contributes to the limited research on success factors for sharing economy startups by identifying human capital and entrepreneurial footprint as having a large necessary effect on fundraising success, and innovativeness only having a medium necessary effect. In terms of practicality, our findings further suggest that a range of $30 \%$ to $40 \%$ level of the three factors is necessary to achieve at least a $40 \%$ performance level in fundraising success, suggesting that these factors have a threshold value to success. We encourage future studies to look at other complementary factors that can increase the performance level of these three factors. 
The rest of the paper is as follows. We start by reviewing the literature on sharing economy success, present our conceptual model, and make a case for a Necessary Condition Analysis. Next, we present our methodology and findings, and conclude our paper with a discussion of the implications for research and practice.
$[1,6]$, prior studies have therefore focused mostly on consumer-level issues such as how to engage participants in the sharing economy [7, 11], what value propositions attract customers [2, 12], and what keeps consumers loyal to a particular sharing platform [13]. These studies have been helpful to unveil how consumers perceive the value of a sharing economy to

Table 1: Studies on the Sharing Economy Success/Failure Factors

\begin{tabular}{|l|l|l|}
\hline Settings & Success/Failure Factors & References \\
\hline $\begin{array}{l}\text { Interviews of 17 sharing economy } \\
\text { businesses and analysis of 521 } \\
\text { sharing platforms over 35 months }\end{array}$ & $\begin{array}{l}\text { Seven failure factors: lack of providers; insufficient analysis } \\
\text { of the sharing market; trust and safety concerns (due to low } \\
\text { control over service quality); hidden resource requirements; } \\
\text { unscalable technical design; unclear legal environment; } \\
\text { business termination through acquisition. }\end{array}$ & \\
\hline $\begin{array}{l}\text { A regression analysis of factors that } \\
\text { predict the growth of Uber }\end{array}$ & $\begin{array}{l}\text { Population and number of licensed taxis predict growth while } \\
\text { unemployment rate, GDP, and population density are } \\
\text { unrelated. }\end{array}$ & {$[9]$} \\
\hline $\begin{array}{l}\text { Interviews of 21 sharing economy } \\
\text { businesses and analysis of 73 } \\
\text { sharing platforms over 2 years }\end{array}$ & $\begin{array}{l}\text { Six failure factors: low customer lock-in; low control over } \\
\text { service quality; high competition for 'idle' resources; low } \\
\text { transaction frequency; high costs of developing two market } \\
\text { sides; unexpected changes in legal environment. }\end{array}$ & {$[6]$} \\
\hline $\begin{array}{l}\text { A four-stage Delphi study with 25 } \\
\text { experts in the sharing economy }\end{array}$ & $\begin{array}{l}\text { Economic drivers are most important, followed by } \\
\text { technological and social/cultural drivers. Environmental } \\
\text { drivers are considered of minor importance. }\end{array}$ & [4] \\
\hline
\end{tabular}

\section{Theoretical Foundation}

\subsection{Sharing economy success}

There are many terms describing the sharing economy: collaborative consumption, collaborative economy, access economy, peer-to-peer economy, platform economy, gig economy, crowd-based capitalism, and on-demand economy [1]. All refer to an emerging phenomenon with a unique setting: companies leverage digital technologies to create an online platform that allows participants to gain temporary access to underutilized assets from their peers. These peer-to-peer transactions create value for both the supply and demand side: the participants as suppliers can capitalize on unused assets without any significant financial investment, and the participants as consumers can get access to needed resources at an affordable price while generating social and emotional value [2].

The rise of the sharing economy model has become disruptive to many industries [10], and researchers have started to examine the phenomenon closely. A recent study showed that sharing economy startups have a high failure rate, with 122 out of 521 sharing economy platforms going out of business within three years of operation [5]. Because scalability and critical mass are critical for the survivability of sharing economy startups participate and remain active.

However, there is a scarcity of research on what determines the entry and growth of sharing economy businesses at the platform level. A recent review study found that out of 25 empirical studies on the sharing economy, 17 were conducted at the consumer level, five at the service provider level, and only three at the platform level [1]. Our own literature review also yields only four empirical studies of success factors for sharing economy platforms (see Table 1). Among them, none was conducted at the entry level, that is, focusing on success factors for sharing economy startups from the investor perspective. All four studies focused on the perspective of business managers. This is a missing research opportunity as research on success factors at the entry level will help increase the chance of success for sharing economy businesses in later stages or when facing crises like the Covid-19 pandemic [8].

In sum, given the dearth of research on the entry level of the sharing economy, the high failure rate of sharing economy business [5], and the significant impact of the Covid-19 pandemic on sharing economy businesses [8], we seek to understand what determines the success of sharing economy startups. Next, we present our conceptual model. 


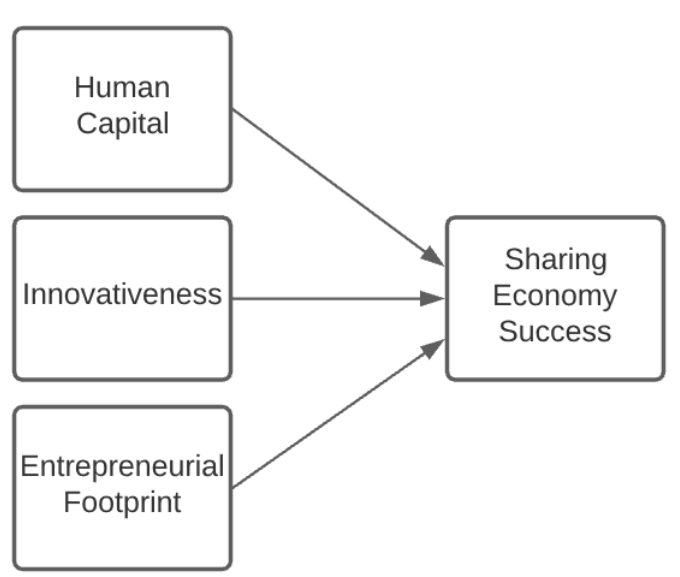

Figure 1: Conceptual Model

\subsection{Conceptual Model}

We define the success of sharing economy startups as the ability to attract funding from investors. In the early stages of a sharing economy startup, the amount of funds a startup can raise through venture capital or crowdsourcing is a substantial indicator of its current success and future growth as greater financial capital allows for more strategic differentiation and nonimitable strategies [14]. The amount of funding raised through crowdsourcing has been a primary source of funding for many sharing economy startups [10]; and has consistently been used in entrepreneurial research as a signal for startup success $[15,16]$.

Our conceptual model for the success of sharing economy startups (Figure 1) is built on three related bodies of literature: the human capital research $[17,18]$, the innovation studies in entrepreneurship research [19], and the network effect research $[1,6]$. These concepts were chosen due to their prominent influences from existing entrepreneurship studies [18, 20, 19, 21].

Human capital is defined as skills and knowledge that individuals process and acquire through various types of experience [17]. Within the entrepreneurial research, human capital has long been attributed to startup growth and profitability [18, 14]. Specifically, prior studies have suggested that high human capital increases the startup's ability to discover and exploit business opportunities [22], positively relates to the planning and strategizing capabilities [23], is effective in acquiring necessary resources $[14,24]$, and is essential in accumulating new knowledge and skills [18]. Because sharing economy startups are built through digital platforms, employees need to have a wide range of business and technical skills to develop

\footnotetext{
${ }^{1}$ This concept is parallel to the concept of environmental footprint in sustainability research which measures the impact of human activities on the environment
}

and update online platforms, manage regular tasks, and troubleshoot technical issues. Several studies have indeed demonstrated how human capital plays a key role in the management of technologically innovative ventures [25]. Thus, we propose that human capital can be a necessary condition for the success of sharing economy startups.

Innovativeness of a startup is broadly defined as the degree to which a new startup develops and introduces new products or services [19]. The link between a startup's innovativeness and its success is supported by a number of theoretical arguments: from the economics perspective, a startup's innovativeness improves its market power and overcome competition [26]; and from the capability perspective, a startup's innovativeness leads to its enhanced absorptive capabilities and increased dynamic capabilities [27, 28]. Various empirical studies have found a positive relationship between innovativeness and a venture's performance. For instance, Helmers and Rogers [29] found that intellectual property (e.g., patents and trademarks) was associated with lower probability of exiting for newly incorporated firms in 2001; Conti, et al. [30] revealed patents as a form of signaling for a high-tech startup's worth and future potential; and a meta-analysis by Song, et al. [19] found that patents are positively linked to new ventures' performance. Therefore, we propose that a startup's innovativeness can be a necessary condition for its success.

Another major success factor for sharing economy businesses is network effect - the ability to remain attractive to participants as the business grows, thus achieving a critical mass of participants for sustainability $[6,31]$. Network effect has been found to be critical in any venture that relies on a network of users as it creates a herding effect on participants and stakeholders that continuously foster its growth; and prior studies have examined a range of positive signals that a venture can give off to initiate this network effect: founder's characteristics, patents and trademarks, quality of websites and marketing materials, firm's resources, among others $[30,19]$. In this study, we propose a novel concept called entrepreneurial footprint ${ }^{1}$ defined as the perceived reputation of a startup from engagement in the entrepreneurial community. Positive activities such as awards, recognitions, positive media coverage, or community engagement can enhance the reputation of a startup and increase its entrepreneurial footprint; while negative activities such as lawsuits, backlash on social media, or community boycotts will damage the reputation of a startup and decrease its entrepreneurial footprint. This 
concept allows for holistically capturing the impacts of a startup's activities within the entrepreneurial community. Prior studies have suggested that positive reputation can sway investors' opinions and create a herding effect among potential investors $[32,33]$. Thus, we propose that entrepreneurial footprint can be a necessary condition for the success of sharing economy startups.

\subsection{Necessary condition analysis}

A necessary (but not sufficient) condition is a condition must be present for the outcome to be realized, but its presence does not guarantee the outcome. In other words, it is a constraint or a bottleneck that must be managed for the outcome to happen [34]. In this study, we employ a novel method called Necessary Condition Analysis (NCA)[34] to explore the necessary (but not sufficient) conditions for the success of sharing economy startups. Our motivations for using this method are as follows. First, while the popular econometrics approach has been useful in validating what factors matter to a startup's success (e.g., [25], [15], [13]), this approach falls short in examining how such factors matter. That is, the analyses are done in an additive manner with limited consideration for complex configurations of factors [35]. Based on variance analysis, these analyses imply any and every variable can substitute to each other, making them unsuitable for testing necessary conditions [34].

Second, although configurational approaches (e.g., the Qualitative Comparative Analysis (QCA)) exist to overcome the limitations of an econometrics approach, they excel in identifying both necessary and sufficient conditions of an outcome. NCA on the other hand only focuses on necessary but not sufficient conditions, thus allowing researchers to "test theories without having to give attention to the full causal structure" [36](p. 927). Subsequently, NCA can identify more necessary conditions than most configurational analyses. Finally, while configurational approaches often rely on settheoretical techniques to identify what factors can act as a necessary condition (necessary condition in-kind), NCA is rooted in calculus which allows a more in-depth analysis and specifies the level of a necessary condition for a given level of outcome (necessary condition indegree) [37, 38].

NCA is an innovative and emerging method that has been increasingly used in research to explore necessary conditions in situations where knowing the necessity in-degree is important. For example, van der Valk, et al. [39] found a minimum level of contractual detail with a high level of trust is a necessary condition for successful buyer-seller relationships; Knol, et al. [40] identified different sets of success factors that were associated with different stages of implementing lean practices, implying a progression and bottom up approach for lean manufacturing; or Delgosha, et al. [41] identified different configurations of IT infrastructure and capabilities can result in different degrees of sustainable competitiveness. For sharing economy startups, knowing what level of a condition can be a necessary condition for a given outcome is useful to allow them to prioritize their limited resources for where they matter the most. Thus, we proceed to apply NCA on our research model to explore what factors can be necessary conditions for the success of sharing economy startups.

\section{Methodology}

\subsection{Data collection}

To identify necessary conditions for sharing economy success, we collected data on sharing economy startups listed in Crunchbase, one of the top open-source databases for private startups in the U.S. Compared to other databases, Crunchbase database has a greater amount of data, is more reliable, and has been consistently used in entrepreneurship research [42]. To collect data, we first searched the Crunchbase database for U.S. startups that utilize the sharing economy business models. This information is often listed in the description keywords of the company. A total of 239 startups were first identified. We then cross-checked the nature of the startups with their websites for accuracy. For each company, we then collected data about the funding amount, number of employees, number of patents, and number of entrepreneurial lists that feature the company. After the verification process of the company's data and elimination of missing data, our final dataset contains 99 startups. Next, we describe the data collection for each variable in detail. The descriptive statistics of our data are presented in Table 2.

Dependent Variable: Funding Amount. We use funding amount as the proxy for startup success. This is the total amount of money that a startup is able to raise through funding initiatives. It is a common proxy for startup success in entrepreneurship research [42, 43, $15]$.

Independent variable: Human Capital. We captured the human capital by using the total number of employees. Because our dataset includes startups using the same business model, sharing economy, this is an appropriate approach to measure human capital of the startup as prior research has suggested that larger entrepreneurial teams are more likely to raise funding than smaller teams [15]. Crunchbase does not provide an exact number of employees, but only an estimation. 
We transformed the estimation into a value range of 1 to 4. Specifically, a value of 1 means that the startup has 1 to 11 employees, a value of 2 means the startup has from 11 to 50 employees, a value of 3 means the startup has between 51 and 100 employees, and the value of 4 means the startup has 101 to 250 employees. In our dataset, no startup has more than 250 employees.

Independent variable: Innovativeness. We captured the innovativeness of a startup by using the number of patents each startup has registered with the US Patent and Trademark Office. Prior research has suggested that startups that hold patents will send a positive signal to potential investors, thus are more likely to attract investment [15, 44, 29, 19]. Given that all startups in our dataset have the same business model, the number of patents a startup holds will send a stronger signal to investors about the innovativeness of the startup.

Independent variable: Entrepreneurial Footprint. We operationalized the entrepreneurial footprint using the number of times a startup has been featured in an entrepreneurial list. Crunchbase frequently scouts new businesses and compiles lists of potential startups to inform investors of up-and-coming startups ${ }^{2}$. For different topics, Crunchbase will have different lists. For instance, list of top 500 startups, list of blue-collar startups, list of AI startups, among other things. Other lists focus on different managerial aspects such as growth potential, social viability, or future profitability, to name a few. Thus, the more entrepreneurial lists a startup appears in, the more popular it will become and the higher the chance it will attract investment.

Table 2: Descriptive Statistics

\begin{tabular}{|l|l|l|l|l|l|}
\hline Variable & Mean & Median & Min & Max & $\begin{array}{l}\text { Standard } \\
\text { Deviation }\end{array}$ \\
\hline $\begin{array}{l}\text { Funding Amount } \\
\text { (in hundred } \\
\text { thousand) }\end{array}$ & 11.09 & 1.40 & 0.02 & 331.5 & 38.97 \\
\hline Human Capital & 1.54 & 1.00 & 1 & 4 & 0.73 \\
\hline Innovation & 0.07 & 0.00 & 0 & 3 & 0.38 \\
\hline $\begin{array}{l}\text { Entrepreneurial } \\
\text { Footprint }\end{array}$ & 62.84 & 57.00 & 9 & 206 & 35.30 \\
\hline
\end{tabular}

\subsection{Data analysis}

We conducted a Necessary Condition Analysis (NCA) [34] to identify the necessary conditions for sharing economy startups as well as the degree of necessity these conditions impose on success. To conduct NCA, we used the NCA package in R (version 3.1.0) [45]. The NCA follows the following steps [34, 36]:

\footnotetext{
${ }^{2}$ https://www.crunchbase.com/featured accessed 5/10/2021
}

Step 1: Creating scatter plots and drawing the ceiling line. In the first step of NCA, we created scatter plots using a Cartesian coordinate system in which the $\mathrm{Y}$ axis represents the outcome variable (Funding Amount) and the $\mathrm{X}$ axis represents the independent variables (Human Capital, Innovativeness, or Entrepreneurial Footprint). These scatter plots allow a visual inspection of the relationship between predictors and outcomes, and if there is an empty space in the upper left corner of the plot, it suggests that a necessary condition of $\mathrm{X}$ for $\mathrm{Y}$ may exist, and the size of the empty space indicates the level of constraint that a predictor imposes on the outcome [34]. Then a ceiling line that separates the empty space and the full space with observations can be drawn. This ceiling line indicates the level of the necessary condition for a given level of outcome. Various techniques exist to draw the ceiling lines. Following the recommendation from Dul [34], we adopted the Ceiling Environment - Free Disposal Hul (ce-fdh) technique which provides greater flexibility and accuracy compared to other techniques.

Step 2: Quantifying NCA parameters and testing for significance. In the second step, we quantified the two main NCA parameters, the necessity effect size and the accuracy [34]. The effect size is the ratio of the empty space in comparison to the total space in the scatter plots. The greater the effect size, the stronger the necessary effect a condition has over the outcome. Relatedly, we also calculated the accuracy of the ceiling technique by taking the number of observations on or below the ceiling line divided by the total number of observations and multiplied by $100 \%$. Because of the nature of the ce-fdh technique which draws step ceiling lines instead of straight lines, the accuracy of the technique is $100 \%$.

In addition, we also conducted a statistical significance test to determine whether the emergence of the necessary condition is by chance [46]. The test is an approximate permutation test against the null hypothesis that the observed effect was due to chance. If the $p$-value is significant, one can reject the null hypothesis that the necessary effect is a result of a random combination of unrelated variables [45].

Step 3: Formulating the necessary conditions. In the last step, the necessary conditions are identified and discussed in light of theories. We also conduct a bottleneck analysis to allow us to understand the degree of necessary effect, as well as to understand how the combinations of necessary conditions may impose constraint on the outcome $[34,36]$. 


\section{Findings}

In this section we report the results of the NCA. Figure 2-4 are the scatter plots that reflect the relationship between the outcome variable (Funding Amount) and each individual predictor, Human Capital, Innovativeness, and Entrepreneurial Footprint, respectively. The dotted redline represent the ceiling line drawn by the ce-fdh technique. The ceiling line separate the "empty space" which captures space without observations and the "full space" which capture all possible space for observations in the dataset. The empty space in the upper left corner also represents the possibility of a necessary condition. Figures 2 to 4 all show empty space for Human Capital, Innovativeness, and Entrepreneurial Footprint, indicating that they all can possibly act as a necessary condition for the Funding Amount outcome. Notably, the empty space for Human Capital and Entrepreneurial Footprint is slightly bigger than the empty space for the Innovativeness, implying that the former has larger necessary effects than the latter.

Table 3 provides greater detail of the NCA and its parameters. The "accuracy" parameter refers to the accuracy of the ce-fdh ceiling line technique. Because this technique draws step ceiling lines instead of straight lines, it is not surprising that it has a $100 \%$ accuracy [34]. The "scope" parameter in the table refers to the empirical area of possible $\mathrm{X}-\mathrm{Y}$ combinations in the scatter plots, and it is calculated using the minimum and maximum observed $\mathrm{X}$ and $\mathrm{Y}$ values. The "ceiling zone" parameter refers to the size of the empty space in the scatter plots, while the "effect size" is calculated by dividing the ceiling zone by the scope. The effect size has a range of 0 to 1 . The greater the effect size, the greater the necessary effect of the condition on the outcome. Dul [34] suggested that values less than 0.1 indicate a small effect, values between 0.1 and 0.3 suggest a medium effect, values between 0.3 and 0.5 represent a large effect, while values greater than 0.5 are signs of a large effect. According to Table 2, Human Capital and Entrepreneurial Footprint have a large necessary effect while Innovativeness has a medium effect on Funding Amount. In other words, funding amount is more sensitive to the Human Capital and Entrepreneurial Footprint than to the Innovativeness.

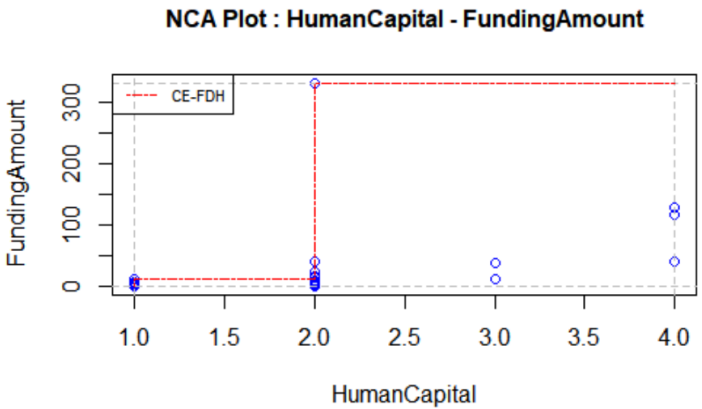

Figure 2: Scatter plot of the relationship between Human Capital and Funding Amount

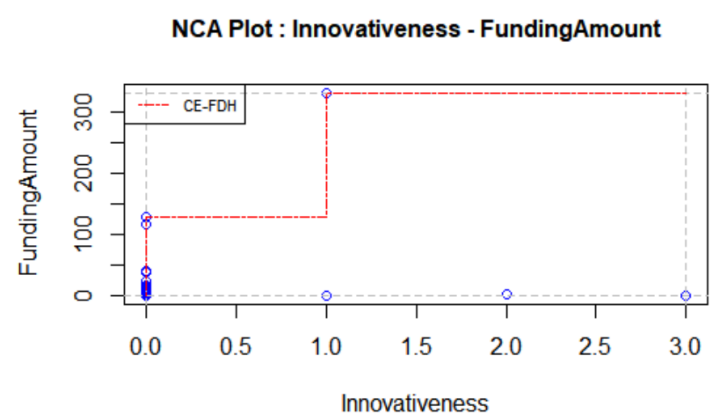

Figure 3: Scatter plot of the relationship between Innovativeness and Funding Amount

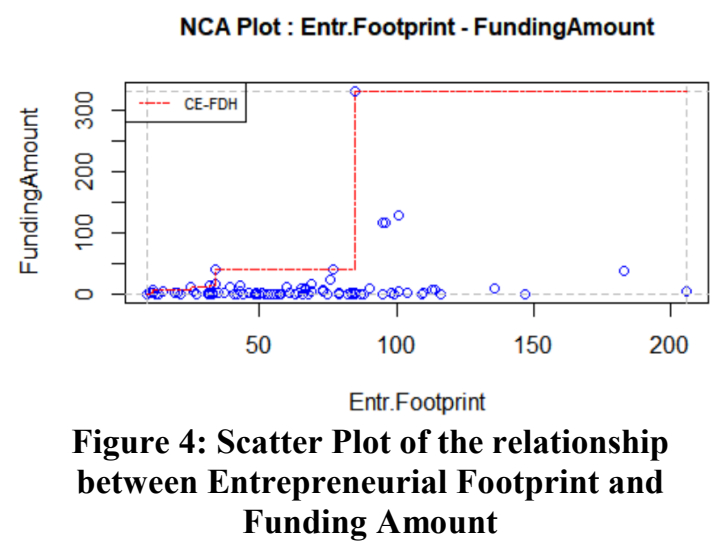

Table 3 also shows the p-value of the significance test for the three conditions. According to the results, it can be argued that the necessary effect of Innovativeness is statistically significant at the 0.05 threshold while the effect of Human Capital and Entrepreneurial Footprint is statistically significant at the 0.1 threshold. We therefore reject the null hypothesis that the observed effects are due to randomness. 
Table 3: NCA Parameters

\begin{tabular}{|l|l|l|l|l|l|l|}
\hline Condition & Accuracy (\%) & Scope (S) & Ceiling zone (C) & Effect size (d=C/S) & $\begin{array}{l}\text { p- } \\
\text { value }\end{array}$ & $\begin{array}{l}\text { p- } \\
\text { accuracy }\end{array}$ \\
\hline Human Capital & $100 \%$ & 994.44 & 318.8 & 0.321 & 0.058 & 0.005 \\
\hline Innovativeness & $100 \%$ & 994.44 & 202.5 & 0.204 & 0.042 & 0.004 \\
\hline $\begin{array}{l}\text { Entrepreneurial } \\
\text { Footprint }\end{array}$ & $100 \%$ & $65,301.56$ & $22,954.87$ & 0.352 & 0.089 & 0.006 \\
\hline
\end{tabular}

Table 4 shows the results of the bottleneck analysis in which all three conditions are tested in combination to examine their effect on different levels of outcome. In other words, it shows which level of condition $\mathrm{X}$ is necessary for a specific level of outcome Y; thus, it represents necessary conditions in degree. The first column represents the performance value of the outcome, expressed as percentage of the range of observed values [45]. Other columns show the level for each condition that corresponds to a given outcome level. NN stands for not necessary. Consistent with the Table 3 results, Human Capital and Entrepreneurial Footprint have an early effect on Funding Amount. Specifically, Human Capital is necessary for as little as $10 \%$ performance level of the Funding Amount, while even $12.7 \%$ of Entrepreneurial Footprint is necessary for the 10\% performance level of the Funding Amount. Innovativeness does not matter until the $40 \%$ performance level of the Funding Amount. In addition, starting from the $40 \%$ performance level of the Funding Amount, it is necessary to have all three conditions represented, indicating that the three conditions are effective together in attracting funding. However, the level required for all three conditions remains below $40 \%$, suggesting that a startup does not need a high level of these conditions to be effective in attracting funding.

Table 4: Bottleneck Analysis

\begin{tabular}{|c|c|c|c|}
\hline $\begin{array}{l}\text { Funding } \\
\text { Amount } \\
(\%)\end{array}$ & $\begin{array}{l}\text { Human } \\
\text { Capital }\end{array}$ & Innovativeness & $\begin{array}{l}\text { Entrepreneurial } \\
\text { Footprint }\end{array}$ \\
\hline 0 & $\mathrm{NN}$ & $\mathrm{NN}$ & $\mathrm{NN}$ \\
\hline 10 & 33.3 & $\mathrm{NN}$ & 12.7 \\
\hline 20 & 33.3 & $\mathrm{NN}$ & 38.6 \\
\hline 30 & 33.3 & $\mathrm{NN}$ & 38.6 \\
\hline 40 & 33.3 & 33.3 & 38.6 \\
\hline 50 & 33.3 & 33.3 & 38.6 \\
\hline 60 & 33.3 & 33.3 & 38.6 \\
\hline 70 & 33.3 & 33.3 & 38.6 \\
\hline 80 & 33.3 & 33.3 & 38.6 \\
\hline 90 & 33.3 & 33.3 & 38.6 \\
\hline 100 & 33.3 & 33.3 & 38.6 \\
\hline
\end{tabular}

\section{Discussion and Conclusion}

This study explores what factors are necessary for the success of sharing economy startups. Our findings contribute to the scarce literature of sharing economy startups by examining how human capital, innovativeness, and entrepreneurial footprint contribute towards the startups' success. Specifically, we found that human capital and entrepreneurial footprint have a large necessary effect on funding amount while innovativeness has only a medium necessary effect. This is consistent with prior studies which have found ample evidence for the significant link between these factors and startups' performance [25, 19, 18, 23]. In addition, our findings show that a range of $30 \%$ to $40 \%$ level of the three factors is necessary to achieve at least $40 \%$ performance level in fundraising success, but this effect remains stable up to the $100 \%$ performance level in fundraising success (Table 4). This suggests that these factors have a threshold value to success; once they reach the $30-40 \%$ threshold their values are fixed. This perhaps explains some contradictory results in the literature where researchers have found that innovativeness can hinder a startup's success [47]; different types of human capital can lead to different performance by startups [18]; or social influence and intellectual properties have no impact on funding success [16]. We encourage future studies to look at this possible threshold value, or consider the possibility of other complementary conditions that can strengthen the necessary effects of these three conditions.

Additionally, we make two other contributions to research. First, we propose the novel concept of entrepreneurial footprint as an alternative concept for a firm's reputation within the entrepreneurial community. Because the concept focuses mostly on community recognitions, it is more suitable for sharing economy startups which usually start with a digital presence rather than the tradition brick-and-mortar presence. Second, our study illustrates the use of the novel NCA as a possible method to study necessary conditions in entrepreneurial research. We encourage future studies to consider this method in studying other entrepreneurial contexts. 
Our findings also provide practical strategies to sharing economy startups. Because sharing economy startups leverage digital technologies to enable peer-topeer transaction, the high necessary effects of human capital and entrepreneurial footprint imply that startup founders and managerial teams should prioritize their resources to strengthen their core team and increase entrepreneurial footprint through social media or community engagement [33]. Particularly, the entrepreneurial footprint will attract more participants in the sharing economy and increase the possibility of a critical mass for success. Additionally, achieving patents or trademarks will also boost the chance of getting higher funding. However, these efforts should be closely monitored to avoid overspending resources on these factors because they only act as necessary conditions with threshold value to success.

The merits of the study should be considered with regards to its limitations. First, while we measure success by the funding amount, it may be possible to measure success using other means such as market shares or successful exist strategies. Additionally, startup failure can also be an outcome measurement itself, and we encourage future studies to contrast success factors of successful versus fail startups. Second, the study does not differentiate startups' success across different stages of operations. A longitudinal analysis will yield additional insight. Third, our predictors only account for $30 \%-40 \%$ of success, so it is very possible that other important factors can increase success chance here. Finally, the data are collected in a single database which contains mostly US startups, thus the findings are not generalizable to startups in different contexts.

Notwithstanding these limitations, we hope our study provides a refreshing look at the necessary conditions for sharing economy startups, an understudied topic. We also hope our novel NCA will inspire others to try out this emerging and innovative method.

\section{References}

[1] O. Gerwe and R. Silva, "Clarifying the Sharing Economy: Conceptualization, Typology, Antecedents, and Effects", Academy of Management perspectives, 34 (2020), pp. 65-96.

[2] T. C. Zhang, H. Gu and M. F. Jahromi, "What Makes The Sharing Economy Successful? An Empirical Examination Of Competitive Customer Value Propositions", Computers in Human Behavior, 95 (2019), pp. 275-283.

[3] J. Manyika, S. Lund, J. Bughin, K. Robinson, J. Mischke and D. Mahajan, Independent Work: Choice, Necessity, And The Gig Economy, McKinsey Global Institute, 2016.
[4] S. J. Barnes and J. Mattsson, "Understanding Current And Future Issues In Collaborative Consumption: A FourStage Delphi Study", Technological Forecasting \& Social Change, 104 (2016), pp. 200-211.

[5] F. Chasin, M. von Hoffen, B. Hoffmeister and J. Becker, "Reasons for Failures Of Sharing Economy Businesses", MIS Quarterly Executive, 17 (2018), pp. 185-199.

[6] K. Täuscher and J. Kietzmann, "Learning from Failures in the Sharing Economy", MIS Quarterly Executive, 16 (2017), pp. 253-263.

[7] J. Hamari, M. Sjöklint and A. Ukkonen, "The Sharing Economy: Why People Participate In Collaborative Consumption", Journal of the Association for Information Science and Technology, 67 (2016), pp. 2047-2059.

[8] M. Hossain, "The Effect Of The Covid-19 On Sharing Economy Activities", Journal of Cleaner Production, 280 (2021), pp. 124782.

[9] J. V. Hall and A. B. Krueger, "An Analysis of the Labor Market for Uber's Driver-Partners in the United States", ILR Review, 71 (2018), pp. 705-732.

[10] A. Sundararajan, The Sharing Economy: The End of Employment and the Rise of Crowd-Based Capitalism, The MIT Press, Boston, MA, 2016.

[11] Z. W. Y. Lee, T. K. H. Chan, M. S. Balaji and A. Y.-L. Chong, "Why People Participate In The Sharing Economy: An Empirical Investigation Of Uber", Internet Research, 28 (2018), pp. 829-850.

[12] S.-L. Huang and M.-Y. Kuo, "Critical Success Factors In The Sharing Economy: A Customer Perspective", Service Business, 14 (2020), pp. 553-576.

[13] S. Yang, Y. Song, S. Chen and X. Xia, "Why Are Customers Loyal In Sharing-Economy Services? A Relational Benefits Perspective", Journal of Services Marketing, 31 (2017), pp. 48-62.

[14] A. C. Cooper, F. J. Gimeno-Gascon and C. Y. Woo, "Initial Human And Financial Capital As Predictors Of New Venture Performance", Journal of Business Venturing, 9 (1994), pp. 371-395.

[15] S. Mamonov and R. Malaga, "Success Factors in Title III Equity Crowdfunding in the United States", Electronic Commerce Research And Applications, 27 (2018), pp. 65-73.

[16] G. K. C. Ahlers, D. Cumming, C. Günther and D. Schweizer, "Signaling in Equity Crowdfunding", Entrepreneurship Theory and Practice, 39 (2015), pp. 955-980.

[17] G. S. Becker, Human Capital: A Theoretical and Empirical Analysis, with Special Reference to Education, The University of Chicago Press, Chicago, IL, 1964.

[18] J. M. Unger, A. Rauch, M. Frese and N. Rosenbusch, "Human Capital And Entrepreneurial Success: A MetaAnalytical Review", Journal of Business Venturing, 26 (2011), pp. 341-358.

[19] M. Song, K. Podoynitsyna, H. Van Der Bij and J. I. M. Halman, "Success Factors in New Ventures: A Metaanalysis", The Journal Of Product Innovation Management, 25 (2008), pp. 7-27.

[20] H. Hoang and B. Antoncic, "Network-Based Research In Entrepreneurship: A Critical Review", Journal of Business Venturing, 18 (2003), pp. 165-187. 
[21] J. Santisteban and D. Mauricio, "Systematic Literature Review Of Critical Success Factors Of Information Technology Startups", Academy of Entrepreneurship Journal, 23 (2017), pp. 1-23.

[22] S. Shane and S. Venkataraman, "The Promise Of Entrepreneurship As A Field Of Research", Academy of Management Review, 25 (2000), pp. 217-226.

[23] J. R. Baum, E. A. Locke and K. G. Smith, "A Multidimensional Model of Venture Growth", Academy of Management Journal, 44 (2001), pp. 292-303.

[24] C. G. Brush, P. G. Greene and M. M. Hart, "From Initial Idea to Unique Advantage: The Entrepreneurial Challenge of Constructing a Resource Base", The Academy of Management Executive, 15 (2001), pp. 6480.

[25] A. BarNir, "Starting Technologically Innovative Ventures: Reasons, Human Capital, And Gender", Management Decision, 50 (2012).

[26] J. A. Schumpeter, "The Theory of Economic Development: An Inquiry into Profits, Capital, Credit, Interest, and the Business Cycle", (1968).

[27] D. J. Teece, G. Pisano and A. Shuen, "Dynamic Capabilities and Strategic Management", Strategic Management Journal, 18 (1997), pp. 509-533.

[28] W. M. Cohen and D. A. Levinthal, "Absorptive Capacity: A New Perspective on Learning and Innovation", Administrative Science Quarterly, 35 (1990), pp. 128152.

[29] C. Helmers and M. Rogers, "Innovation and the survival of new firms in the UK", Review of Industrial Organization, 36 (2010), pp. 227-248.

[30] A. Conti, M. Thursby and F. T. Rothaermel, "Show Me the Right Stuff: Signals for High-Tech Startups", Journal of Economics \& Management Strategy, 22 (2013), pp. 341-364.

[31] G. G. Parker, M. W. Van Alstyne and S. P. Choudary, Platform Revolution: How Networked Markets Are Tranforming the Economy and How to Make Them Work for You, W. W. Norton \& Company Ltd., New York, NY, 2016.

[32] M. J. Dollinger, P. A. Golden and T. Saxton, "The Effect Of Reputation On The Decision To Joint Venture", Strategic Management Journal, 18 (1997), pp. 127-140.

[33] A. P. Petkova, "How to Judge What Can't be Seen and Touched? The Contingent Effect of Media Reputation on Young Firms' Access to Venture Capital", Corporate Reputation Review, 17 (2014), pp. 273-289.

[34] J. Dul, "Necessary Condition Analysis (NCA): Logic and Methodology of "Necessary but Not Sufficient" Causality", Organizational Research Methods, 19 (2016), pp. $10-52$

[35] P. C. Fiss, "A Set-Theoretic Approach to Organizational Configurations", Academy of Management Review, 32 (2007), pp. 1180-1198.

[36] J. Dul, B. Vis and G. Goertz, "Necessary Condition Analysis (NCA) Does Exactly What It Should Do When Applied Properly: A Reply to a Comment on NCA", Sociological Methods \& Research, 50 (2021), pp. 926936.
[37] J. Dul, "Identifying Single Necessary Conditions with NCA and fsQCA", Journal of Business Research, 69 (2016), pp. 1516-1523.

[38] B. Vis and J. Dul, "Analyzing Relationships of Necessity Not Just in Kind But Also in Degree: Complementing fsQCA With NCA", Sociological Methods \& Research, 47 (2018), pp. 872-899.

[39] W. van der Valk, R. Sumo, J. Dul and R. G. Schroeder, "When Are Contracts And Trust Necessary For Innovation In Buyer-Supplier Relationships? A Necessary Condition Analysis", Journal of Purchasing and Supply Management, 22 (2016), pp. 266-277.

[40] W. H. Knol, J. Slomp, R. L. J. Schouteten and K. Lauche, "Implementing Lean Practices In Manufacturing Smes: Testing 'Critical Success Factors' Using Necessary Condition Analysis", International Journal of Production Research, 56 (2018), pp. 3955-3973.

[41] M. S. Delgosha, T. Saheb and N. Hajiheydari, "Modelling the Asymmetrical Relationships between Digitalisation and Sustainable Competitiveness: A Cross-Country Configurational Analysis", Information Systems Frontiers (2020).

[42] S. Bui and Q. N. Bui, "An Empirical Investigation of Equity-based Crowdfunding Campaigns in the United States", in J. J. Xu, B. Zhu, X. Liu, M. J. Shaw, H. Zhang and M. Fan, eds., The Ecosystem of e-Business: Technologies, Stakeholders, and Connections, Springer International Publishing, New York, NY, 2019.

[43] A. Lukkarinen, J. E. Teich, H. Wallenius and J. Wallenius, "Success Drivers of Online Equity Crowdfunding Campaigns", Decision Support Systems, 87 (2016), pp. 26-38.

[44] C. Fisch, "Initial Coin Offerings (ICOs) To Finance New Ventures", Journal of Business Venturing, 34 (2019), pp. $1-22$.

[45] J. Dul, Necessary Condition Analysis (NCA) with $R$ (Version 3.1.0): A Quick Start Guide, 2021.

[46] J. Dul, E. Laan and R. Kuik, "A Statistical Significance Test for Necessary Condition Analysis", Organizational Research Methods, 23 (2018), pp. 385-395.

[47] A. Hyytinen, M. Pajarinen and P. Rouvinen, "Does Innovativeness Reduce Startup Survival Rates?", Journal of Business Venturing, 30 (2015), pp. 564-581. 